\title{
$\beta$ blockers and mortality after myocardial infarction in patients without heart failure: multicentre prospective cohort study
}

\author{
Etienne Puymirat, 1,2,3 Elisabeth Riant,, 1,2,3 Nadia Aissoui, 2,3,4 Angèle Soria, 2,5,6,7 Gregory Ducrocq, 2,8,9,10 \\ Pierre Coste, ${ }^{11,12}$ Yves Cottin,, ${ }^{13,14}$ Jean François Aupetit, ${ }^{15}$ Eric Bonnefoy, ${ }^{16,17}$ Didier Blanchard, ${ }^{18}$ \\ Simon Cattan, ${ }^{19}$ Gabriel Steg, ${ }^{2,8,9,10}$ François Schiele, ${ }^{20,21}$ Jean Ferrières, ${ }^{22,23}$ Yves Juillière, ${ }^{24,25}$ \\ Tabassome Simon, 2,26 Nicolas Danchin ${ }^{1,2,3}$
}

For numbered affiliations see end of article.

Correspondence to: E Puymirat etienne.puymirat@egp.aphp.fr Additional material is published online only. To view please visit the journal online.

Cite this as: BMJ 2016;354:i4801 http://dx.doi.org/10.1136/bmj.i4801

Accepted: 2 September 2016

\section{ABSTRACT}

OBJECTIVE

To assess the association between early and prolonged $\beta$ blocker treatment and mortality after acute myocardial infarction.

DESIGN

Multicentre prospective cohort study.

SETTING

Nationwide French registry of Acute ST- and non-STelevation Myocardial Infarction (FAST-MI) (at 223 centres) at the end of 2005.

PARTICIPANTS

2679 consecutive patients with acute myocardial infarction and without heart failure or left ventricular dysfunction.

\section{MAIN OUTCOME MEASURES}

Mortality was assessed at 30 days in relation to early use of $\beta$ blockers ( $\leq 48$ hours of admission), at one year in relation to discharge prescription, and at five years in relation to one year use.

RESULTS

$\beta$ blockers were used early in $77 \%$ (2050/2679) of patients, were prescribed at discharge in $80 \%$ (1783/2217), and were still being used in $89 \%$ (1230/1383) of those alive at one year. Thirty day mortality was lower in patients taking early $\beta$ blockers (adjusted hazard ratio $0.46,95 \%$ confidence interval 0.26 to 0.82 ), whereas the hazard ratio for one year mortality associated with $\beta$ blockers at discharge was 0.77 ( 0.46 to 1.30$)$. Persistence of $\beta$ blockers at one year was not associated with lower five year mortality (hazard ratio $1.19,0.65$ to 2.18). In contrast, five year mortality was lower in patients continuing statins at one year (hazard ratio $0.42,0.25$ to 0.72 ) compared

\section{WHAT IS ALREADY KNOWN ON THIS TOPIC}

Most randomised controlled trials of $\beta$ blockers after acute myocardial infarction were conducted before the era of reperfusion therapy and modern secondary prevention Their usefulness in patients currently treated for acute myocardial infarction with preserved left ventricular function is debated, leading to divergences between European and American guidelines

\section{WHAT THIS STUDY ADDS}

This analysis from a nationwide French registry shows a decrease over time in the association of $\beta$ blocker treatment with survival in acute myocardial infarction patients without heart failure or left ventricular dysfunction

Early use of $\beta$ blockers at the acute stage of myocardial infarction seems to be associated with a substantial decrease in 30 day mortality

Prolonged $\beta$ blocker treatment beyond one year is unlikely to improve survival with those discontinuing statins. Propensity score and sensitivity analyses showed consistent results.

\section{CONCLUSIONS}

Early $\beta$ blocker use was associated with reduced 30 day mortality in patients with acute myocardial infarction, and discontinuation of $\beta$ blockers at one year was not associated with higher five year mortality. These findings question the utility of prolonged $\beta$ blocker treatment after acute myocardial infarction in patients without heart failure or left ventricular dysfunction.

TRIAL REGISTRATION

Clinical trials NCT00673036.

\section{Introduction}

The benefit of $\beta$ blockers is undisputed in patients with heart failure or left ventricular dysfunction in sinus rhythm and consistent in patients with ischaemic or non-ischaemic systolic heart failure. ${ }^{12}$ Most trials assessing the effect of $\beta$ blockers after acute myocardial infarction were carried out several decades ago, at a time when reperfusion therapy was not used and when currently used secondary prevention drugs such as statins were not available. ${ }^{3}$ In the reperfusion era, the large Clopidogrel and Metoprolol in Myocardial Infarction Trial (COMMIT) had its primary endpoint at 28 days; none of the patients had primary percutaneous coronary intervention, and $45 \%$ of the patients received no reperfusion therapy. ${ }^{4}$ Most patients with acute myocardial infarction, however, including those with preserved left ventricular function, receive $\beta$ blockers at discharge and continue their treatment for years after the acute episode.

The lack of recent evidence on the effect of $\beta$ blockers has resulted in divergences between European and American guidelines, ${ }^{5-8}$ and the role of the long term use of $\beta$ blockers after acute myocardial infarction in patients without heart failure and with adequate left ventricular function is controversial. ${ }^{9}$ The purpose of this study was to assess the associations of $\beta$ blocker use and adherence to treatment with short term and long term mortality by using data from the nationwide French registry of Acute ST-elevation and non-ST-elevation Myocardial Infarction (FAST-MI) 2005. We assessed the relation between $\beta$ blocker use and mortality at three time points: early use (within 48 hours of admission) in relation to 30 day mortality, prescription of $\beta$ blockers at discharge in relation to one year mortality, and persistent use of $\beta$ blockers at one year in relation to five year mortality. 


\section{Methods}

Study design

The population and methods of the FAST-MI registry have been described in detail elsewhere. ${ }^{1011}$ Briefly, the objective of the study was to collect comprehensive data on the management and outcome of consecutive patients admitted to intensive care units for definite acute myocardial infarction over a one month period in France, irrespective of the type of institution to which the patients were admitted (university hospitals, public hospitals, or private clinics, with or without on-site catheterisation facilities). Of the 374 centres that treated patients with acute myocardial infarction at that time, $223(60 \%)$ participated in the study.

All consecutive adult ( $\geq 18$ years) patients admitted to the participating centres during a one month period beginning on 1 October 2005, with a one month extension for patients with diabetes, were included in the registry if they had elevated serum markers of myocardial necrosis higher than twice the upper limit of normal for creatine kinase, creatine kinase-MB, or elevated troponins; had symptoms compatible with acute myocardial infarction and/or electrocardiographic changes on at least two contiguous leads with pathological $Q$ waves and/or persisting ST elevation or depression greater than $0.1 \mathrm{mV}$; and consented to participate in the study. The time from the onset of symptoms to admission to the intensive care unit had to be less than 48 hours. Patients with iatrogenic myocardial infarction, defined as occurring within 48 hours of a therapeutic procedure, and those in whom diagnosis of acute myocardial infarction was invalidated in favour of another diagnosis were excluded from the survey. Patients were not involved in the registry organisation. The patients had to give their informed consent for participation in the study.

\section{Data collection}

Specially trained research technicians who visited each centre at least once a week prospectively recorded all data on computerised case record forms. Cardiovascular history, drug treatment at the time of admission, risk factors, and in-hospital clinical course, including maximal Killip class, as well as initial diagnostic and therapeutic management, were recorded for each patient. Discharge drugs, including type and dose of $\beta$ blockers, were recorded. We considered doses at or above $50 \mathrm{mg} /$ day for atenolol, $100 \mathrm{mg} /$ day for metoprolol, $200 \mathrm{mg} /$ day for acebutolol, or $5 \mathrm{mg} /$ day for bisoprolol to be moderate to high doses.

Follow-up was centralised at the French Society of Cardiology, and dedicated research technicians contacted both the physicians and the patients themselves or their families, after checking the patients' vital status in municipal registers. Information on cardiovascular and non-cardiovascular hospital admissions and drug prescriptions during follow-up was sought; drug use was self reported by the patients and in many instances supported by copies of the medical prescription.

When the patients or their families or physicians reported events that had led to hospital admission, hospital discharge letters and supportive documents were retrieved whenever possible. All events reported were reviewed by at least one member of a three member critical events committee (ND, TS, and Pascal Guéret); the committee reviewed all cases that seemed debatable. Cause of death was assessed in the same way and additionally cross linked with the national database of causes of deaths. For the analysis presented here, we used the following classification: cardiovascular cause, non-cardiovascular cause, cause undetermined; in addition, we categorised mode of death into sudden or non-sudden.

The rates of patients lost to follow-up for vital status were $0.3 \%$ at one year and $4.1 \%$ at five years. The outcome variables used for this study were all cause mortality at 30 days, one year, and five years.

\section{Populations studied}

A first analysis focused on the association between early use of $\beta$ blockers (within 48 hours of admission) and 30 day mortality in patients without previous history of heart failure and without signs of heart failure on admission (Killip class I) (population 1; fig 1). We then analysed the relation between $\beta$ blockers at discharge and one year mortality in the population without history of heart failure and with no sign of heart failure (Killip class I) throughout the hospital stay and without documentation of an ejection fraction of $40 \%$ or below before hospital discharge (using echocardiography, contrast left ventricular angiography, or radionuclide assessment of left ventricular function) (population 2; fig 1). We did a third analysis in the subset of population 2 who had received $\beta$ blockers at discharge and were alive at one year, to determine five year outcome according to persistence of $\beta$ blockers at one year (population 3; fig 1).

Finally, we did an analysis of five year mortality according to persistence of statin treatment at one year in

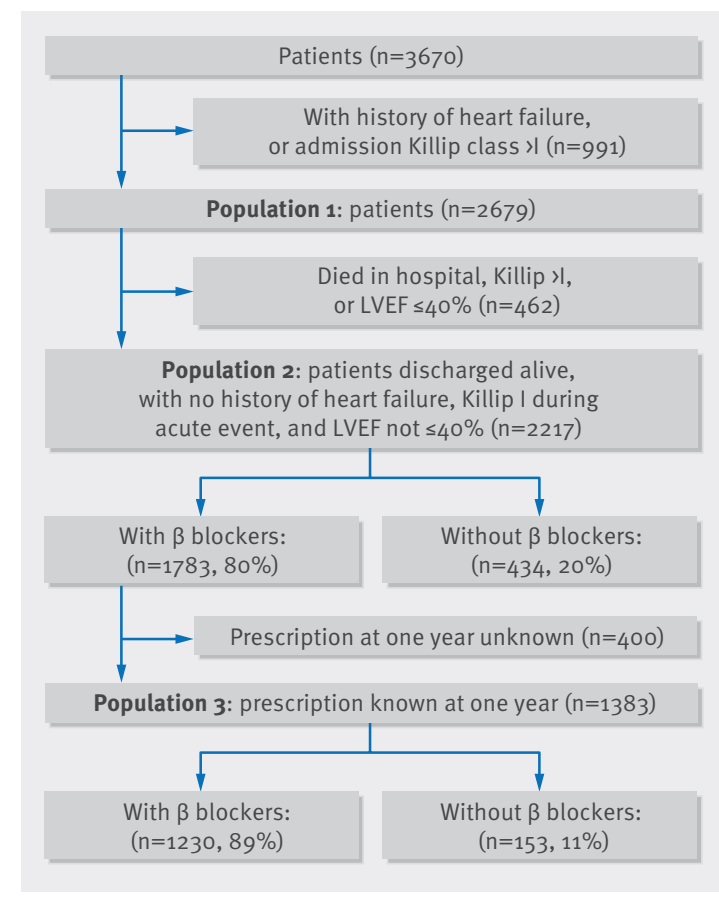

Fig 1 | Flowchart of populations from FAST-MI studied at different time points. LVEF=left ventricular ejection fraction 
population 3 patients who were discharged taking statins. We used this analysis to determine whether its results would be concordant with those of the randomised trials of statins after acute myocardial infarction, which, unlike $\beta$ blocker trials, were conducted in the contemporary era of reperfusion therapy and invasive strategies for patients with acute coronary syndromes.

\section{Statistical analysis}

All continuous variables are described as their mean values with standard deviation or as median and interquartile range. All categorical variables are described using absolute and relative frequency distributions. Comparisons between groups used unpaired $t$ tests or non-parametric Mann-Whitney tests for continuous variables and $\chi^{2}$ tests for discrete variables. We generated survival curves by using the Kaplan and Meier method and used log rank tests to compare them. Patients lost to follow-up were kept in the analyses and censored at the time they were last known to be alive. We used backwards Cox multivariable analyses for assessing the association between $\beta$ blockers and mortality. We used a P value of 0.05 for inclusion and 0.10 for exclusion. We calculated the cumulative hazard functions for each covariate to assess proportionality and verified collinearity by calculating variance inflation factors.

We did several analyses using different sets of covariates for the three populations studied. We selected covariates ad hoc, on the basis of their physiological relevance and potential to be associated with short term or long term mortality. A detailed description of the variables used is provided in appendix 1 of the supplementary material.

In addition, we used non-parsimonious logistic regression analysis to calculate propensity scores for getting $\beta$ blockers at each time point (first 48 hours, discharge, one year), leading to one propensity score for each population. Within each population, we matched one patient not receiving $\beta$ blockers with a given propensity score with one (populations 1 and 2) or three (population 3) patients receiving $\beta$ blockers and having a similar propensity score, by using a greedy procedure based on the Mahalanobis distance within propensity score callipers set at a $0.2^{\star}$ sigma. A first propensity score was calculated in population 1 , and two cohorts were matched with a 1:1 ratio (502 patients each); a second propensity score was calculated in population 2 , with a 1:1 matching procedure (383 patients each); finally, a third propensity score was calculated in population 3, with a 3:1 matching procedure (95 patients who discontinued $\beta$ blockers and 277 with prolonged $\beta$ blocker treatment). Model fits were satisfactory: Hosmer-Lemeshow P value 0.41, C statistic 0.75 for the model in population 1; Hosmer-Lemeshow $P$ value 0.83 , C statistic 0.83 for population 2; and Hosmer-Lemeshow $\mathrm{P}$ value 0.45 , C statistic 0.72 for population 3 . We also used propensity score matching (3:1 matching) to compare patients with continued versus discontinued statin treatment at one year in the population who had received both statins and $\beta$ blockers at discharge. Model fit for continuation of statins at one year: Hosmer-Lemeshow $\mathrm{P}$ value 0.63 , C statistic 0.80 .
We used the IBM-SPSS version 20.0 and NCSS 9 software for all analyses. For all tests, we considered a P value of less than 0.05 (two sided) to be significant.

\section{Patient involvement}

No patients were involved in setting the research question, nor were they involved in developing plans for recruitment, design, or implementation of the study. No patients were asked to advise on interpretation or writing up of results. Patients were contacted personally during follow-up, and we sent them a newsletter on the course of the study and its main findings.

\section{Results}

$\beta$ blockers in first 48 hours and 30 day mortality

Of the 3670 patients included in the registry, 991 had a history of heart failure before the current episode or had Killip class II or higher at admission. Among the 2679 patients included, 2050 (76.5\%) were treated with $\beta$ blockers during the first 48 hours after admission. Patients who were given $\beta$ blockers were younger than those who were not, with a lower GRACE risk score and less comorbidity (table 1). After propensity score matching, the characteristics of the two populations were well balanced (supplementary table A).

Thirty day mortality was $2.3 \%$ in patients who received $\beta$ blockers, compared with $8.6 \%$ in patients who did not (crude hazard ratio $0.26,95 \%$ confidence interval 0.17 to 0.38 ; $\mathrm{P}<0.001$ ), and the difference persisted after multivariable adjustment (hazard ratio $0.46,0.26$ to 0.82 ; $\mathrm{P}=0.008$ ) (fig 2, panel A). In an analysis censoring patients who had died within 48 hours of admission, to avoid immortal time bias, early $\beta$ blocker treatment was still associated with lower 30 day mortality (hazard ratio $0.49,0.26$ to $0.92 ; \mathrm{P}=0.026)$. Propensity score matched cohorts yielded similar results (hazard ratio $0.57,0.36$ to 0.92; $\mathrm{P}=0.02$ ) (supplementary fig A). Cause of death was cardiovascular in $89 \%$ of the patients, both for patients receiving and those not receiving $\beta$ blockers.

Sensitivity analyses excluding patients who died in the first two days after admission showed consistent results (adjusted hazard ratio $0.62,0.31$ to 1.24 ; $\mathrm{P}=0.18$ ). Likewise, we saw no interaction between the pre-specified subgroups (age, sex, type of acute myocardial infarction, left ventricular ejection fraction, use of percutaneous coronary intervention) and the association of early $\beta$ blocker treatment with mortality (supplementary fig B), and no difference existed according to type of $\beta$ blocker used (adjusted hazard ratio ranging from 0.41 to 0.54 ).

\section{$\beta$ blockers at discharge and one year mortality}

In the 2217 patients discharged from hospital with no history of heart failure, no heart failure during the index admission, and left ventricular ejection fraction not $40 \%$ or less, 1783 (80.4\%) were treated with $\beta$ blockers at discharge (fig 1). As for early $\beta$ blocker users, patients with $\beta$ blockers at discharge were younger and had less comorbidity than those without (supplementary table B). After propensity score matching, the two groups of 383 patients with or without $\beta$ blockers at discharge were well balanced (supplementary table $\mathrm{C}$ ). 


\begin{tabular}{|c|c|c|c|}
\hline & $\begin{array}{l}\text { Without } \beta \text { blockers } \\
(n=629)\end{array}$ & $\begin{array}{l}\text { With } \beta \text { blockers } \\
(n=2050)\end{array}$ & $P$ value \\
\hline \multicolumn{4}{|l|}{ Demographics } \\
\hline Mean (SD) age, years & $68.0(13.6)$ & $63.7(13.6)$ & $<0.001$ \\
\hline Age $\geq 75$ years & $232(37)$ & $497(24)$ & $<0.001$ \\
\hline Female sex & $210(33)$ & $539(26)$ & 0.001 \\
\hline \multicolumn{4}{|l|}{ Risk factors } \\
\hline Hypertension & $374(59)$ & $1095(53)$ & 0.008 \\
\hline Hypercholesterolaemia & $299(48)$ & $983(48)$ & 0.85 \\
\hline Current smoking & $173(28)$ & $698(34)$ & 0.002 \\
\hline Diabetes mellitus & $207(33)$ & $645(31)$ & 0.50 \\
\hline Family history of premature CVD & $123(20)$ & $575(28)$ & $<.001$ \\
\hline \multicolumn{4}{|l|}{ Medical history } \\
\hline Previous stroke or TIA & $54(9)$ & $114(6)$ & 0.006 \\
\hline Previous CABG & $36(6)$ & $83(4)$ & 0.07 \\
\hline Previous PCl & $94(15)$ & $245(12)$ & 0.05 \\
\hline Previous MI & $108(17)$ & $280(14)$ & 0.03 \\
\hline Peripheral artery disease & $67(11)$ & $113(6)$ & $<0.001$ \\
\hline Chronic kidney disease & $26(4)$ & $69(3)$ & 0.36 \\
\hline Chronic obstructive lung disease & $51(8)$ & $30(1)$ & $<0.001$ \\
\hline History of cancer & $43(7)$ & $118(6)$ & 0.32 \\
\hline \multicolumn{4}{|l|}{ Drugs before index MI } \\
\hline Antiplatelet agent & $227(36)$ & $535(26)$ & $<0.001$ \\
\hline Statin & $181(29)$ & $532(26)$ & 0.16 \\
\hline$\beta$ blocker & $81(13)$ & $520(25)$ & $<0.001$ \\
\hline ACE inhibitor & $116(18)$ & $324(16)$ & 0.12 \\
\hline Angiotensin receptor blocker & $110(17)$ & $281(14)$ & 0.02 \\
\hline \multicolumn{4}{|l|}{ Index acute $\mathrm{MI}$} \\
\hline STEMI & $335(53)$ & $1161(57)$ & 0.14 \\
\hline LBBB & $23(4)$ & $34(2)$ & 0.002 \\
\hline Atrial fibrillation on admission electrocardiogram & $40(6)$ & $92(4.5)$ & 0.06 \\
\hline Mean (SD) GRACE score & $144(29)$ & $134(28)$ & $<0.001$ \\
\hline Median (IQR) maximal CK, IU/L & $308(146-934) ;(n=427)$ & $544(216-1441) ;(n=1749)$ & $<0.001$ \\
\hline Median (IQR) LVEF, \% & $55(48-65) ;(n=349)$ & $55(49-62) ;(n=1553)$ & 0.67 \\
\hline Coronary angiography $\leq 48$ hours of admission & $412(66)$ & $1634(80)$ & $<0.001$ \\
\hline $\mathrm{PCl}$ in first 48 hours & $249(40)$ & $1055(51)$ & $<0.001$ \\
\hline \multicolumn{4}{|l|}{ Reperfusion therapy in STEMI: } \\
\hline Fibrinolysis & $80(24)$ & $369(32)$ & \multirow[t]{2}{*}{$<0.001$} \\
\hline Primary $\mathrm{PCl}$ & $117(35)$ & $458(39)$ & \\
\hline Coronary bypass graft during stay & $22(3)$ & $88(4)$ & 0.38 \\
\hline LMWH in first 48 hours & $354(56)$ & $1421(69)$ & $<0.001$ \\
\hline Clopidogrel in first 48 hours & $490(78)$ & $1905(93)$ & $<0.001$ \\
\hline Statin in first 48 hours & $372(59)$ & $1721(84)$ & $<0.001$ \\
\hline \multicolumn{4}{|l|}{ Type of $\beta$ blocker used } \\
\hline Acebutolol & - & $462(23)$ & - \\
\hline Atenolol & - & $820(40)$ & - \\
\hline Bisoprolol & - & $448(22)$ & - \\
\hline Metoprolol & - & $208(10)$ & - \\
\hline Other/unknown & - & $112(5)$ & - \\
\hline \multicolumn{4}{|l|}{ Dose of $\beta$ blocker prescribed at discharge $(n=1973)$} \\
\hline$<50 \%$ of optimal & - & $416(21)$ & - \\
\hline$\geq 50 \%$ of optimal & - & $1339(68)$ & - \\
\hline Dose unknown & - & $218(11)$ & - \\
\hline \multicolumn{4}{|c|}{$\begin{array}{l}\text { ACE=angiotensin converting enzyme; } C A B G=\text { coronary artery bypass grafting; } C K=\text { creatine kinase; } C V D=\text { cardiovascular disease; } I Q R=\text { interquartile } \\
\text { range; } L B B B=\text { left bundle branch block; } L M W H=\text { low molecular weight heparin; } L V E F=\text { left ventricular ejection fraction; } M I=\text { myocardial infarction; } \\
\text { PCI=percutaneous coronary intervention; } S T E M I=S T \text { elevation myocardial infarction; } T I A=\text { transient ischaemic attack. }\end{array}$} \\
\hline
\end{tabular}

One year mortality was 3.4\% in patients discharged taking $\beta$ blockers compared with $7.8 \%$ in those without $\beta$ blockers (crude hazard ratio $0.43,0.28$ to 0.65 ; $\mathrm{P}<0.001)$. After full adjustment, the hazard ratio was 0.77 (0.46 to 1.30; $\mathrm{P}=0.32$ ) (fig 2, panel B).
Likewise, in the propensity score matched cohorts, one year mortality was numerically lower in patients with $\beta$ blockers at discharge $(6.3 \%$ versus $7.3 \%$ in those without $\beta$ blockers at discharge; hazard ratio $0.85,0.50$ to $1.47 ; \mathrm{P}=0.57)$. Death from cardiovascular disease at 

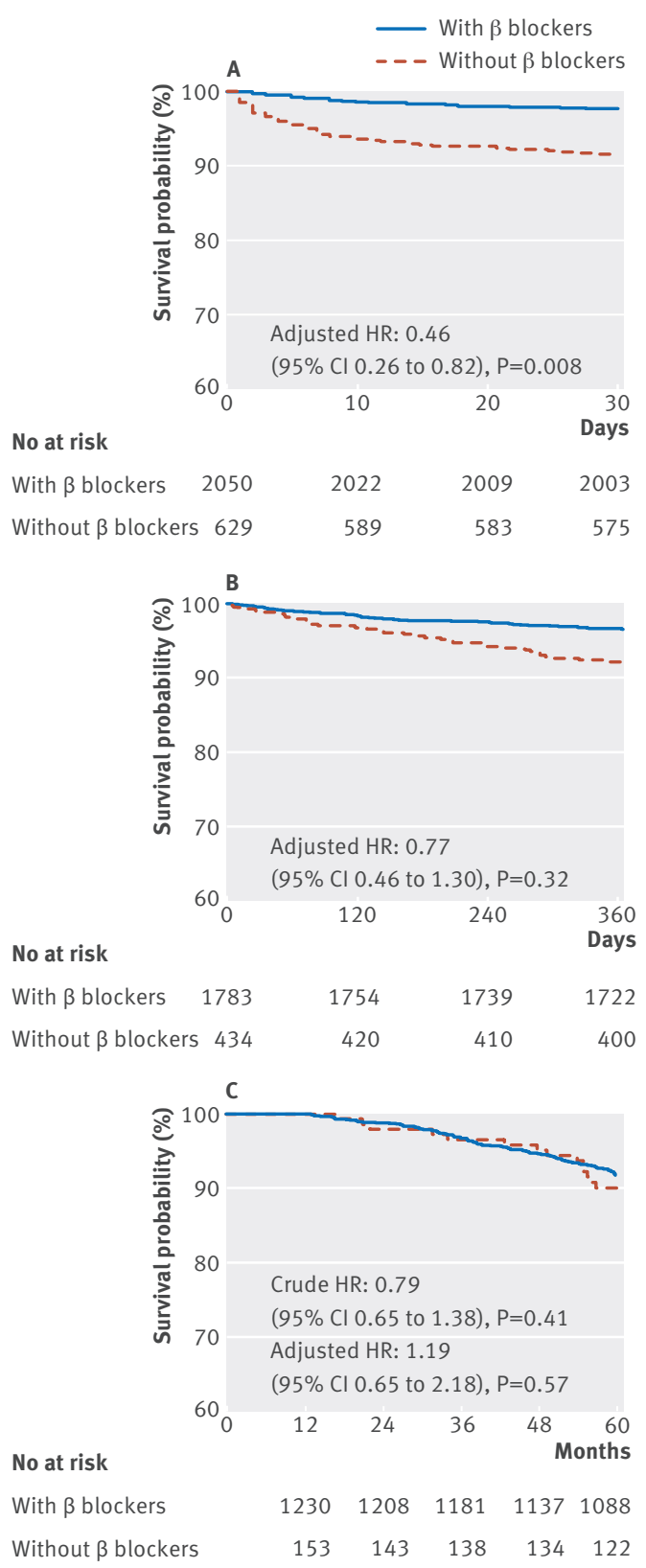

Fig 2 | Survival according to $\beta$ blocker use. A: 30 day survival according to $\beta$ blocker use during first 48 hours after admission in patients with no history of heart failure and no heart failure on admission (population 1). B: one year survival according to $\beta$ blocker prescription at discharge in patients with no history of heart failure and no documented left ventricular dysfunction (population 2). C: five year survival in patients discharged taking $\beta$ blockers, according to continuation of $\beta$ blocker treatment at one year (population 3). HR=hazard ratio

one year was significantly lower in patients receiving $\beta$ blockers at discharge (2.6\% versus $5.5 \%$ in those without $\beta$ blockers; $\mathrm{P}=0.044$ ), but sudden cardiac death was similar (2.6\% in each group). We found no difference in non-cardiovascular mortality (2.1\% without versus $3.1 \%$ with $\beta$ blockers at discharge).

Subgroup analyses according to age, sex, type of myocardial infarction, and left ventricular ejection fraction ( $>50 \%$ and $40-50 \%)$ showed no significant interaction between $\beta$ blockers at discharge and one year survival. Neither type of $\beta$ blockers prescribed at discharge nor dose (28\% taking moderate to high doses) was related to one year mortality after adjustment for age and GRACE score.

\section{Continued $\beta$ blocker treatment at one year and five year mortality}

Among the 1783 patients with $\beta$ blockers at discharge, 1383 were alive at one year and had details of their prescription available (population 3; fig 1). Of those, 153 (11.1\%) had stopped their $\beta$ blockers. Most of the initial characteristics were similar between patients who discontinued $\beta$ blockers and those who did not; however, other secondary prevention drugs at one year were less frequently used in patients who had stopped $\beta$ blockers (table 2). After propensity score matching, the two cohorts (with or without $\beta$ blockers at one year) were well matched (supplementary table D).

Five year mortality was $7.6 \%$ in patients still taking $\beta$ blockers at one year, compared with $9.2 \%$ in those who were no longer taking $\beta$ blockers at one year (crude hazard ratio $0.79,0.45$ to $1.38 ; \mathrm{P}=0.41$ ). The adjusted hazard ratio was 1.19 ( 0.65 to $2.18 ; \mathrm{P}=0.57$ ) (fig 2, panel C). Cause of death was non-cardiovascular in a similar percentage of the patients with ( $45 \%$ ) or without $(35 \%) \beta$ blockers at one year. The adjusted hazard ratio for documented cardiovascular death was 0.90 , and that for death of non-cardiovascular or unknown cause was 0.99 (0.47 to 2.05). Sudden cardiac death was documented in $0.7 \%$ of the patients who had stopped $\beta$ blockers, compared with $0.6 \%$ of those still taking $\beta$ blockers at one year. The results were consistent across all subgroups (supplementary fig C), as well as in the propensity score matched cohorts (hazard ratio 1.10, 0.41 to 2.97 ; $\mathrm{P}=0.85$ ) (supplementary fig D). No heterogeneity existed according to type of $\beta$ blocker used. Five year risk of death, recurrent myocardial infarction, or stroke was $13.7 \%$ in patients without and $10.9 \%$ in patients with persistent $\beta$ blocker treatment at one year: crude hazard ratio 0.76 ( 0.48 to $1.21 ; \mathrm{P}=0.25$ ); adjusted hazard ratio 1.02 ( 0.62 to 1.09 ; $\mathrm{P}=0.94$ ).

In the sensitivity analysis in three year survivors, according to persistence of $\beta$ blocker treatment at three years, the hazard ratio for five year mortality was 1.32 ( 0.51 to 3.37; $\mathrm{P}=0.51$ ) for patients with continued treatment, compared with those with permanent discontinuation at one and three years.

\section{Statin discontinuation after discharge and five year mortality}

Among the 1256 patients who received statins and $\beta$ blockers at hospital discharge, 136 (10.8\%) had stopped statin treatment at one year. Five year mortality was $5.8 \%$ in patients still taking statins at one year, compared with $16.9 \%$ in those who had stopped (crude hazard ratio $0.32,0.20$ to $0.51 ; \mathrm{P}<0.001)$; the adjusted hazard ratio was 0.42 ( 0.25 to 0.72 ; $\mathrm{P}=0.001$ ) (supplementary fig E). Cause of death was non-cardiovascular in $56 \%$ of the patients without statins at one year, 


\begin{tabular}{|c|c|c|c|}
\hline & $\begin{array}{l}\text { Without } \beta \text { blockers } \\
(n=153)\end{array}$ & With $\beta$ blockers $(n=1230)$ & $P$ value \\
\hline \multicolumn{4}{|l|}{ Demographics } \\
\hline Mean (SD) age, years & 64.7 (13.9) & $63.0(12.8)$ & 0.12 \\
\hline Age $\geq 75$ years & $43(28)$ & $255(21)$ & 0.04 \\
\hline Female sex & $46(30)$ & $327(27)$ & 0.36 \\
\hline \multicolumn{4}{|l|}{ Risk factors } \\
\hline Hypertension & $82(54)$ & $655(53)$ & 0.94 \\
\hline Hypercholesterolaemia & $74(48)$ & $612(50)$ & 0.75 \\
\hline Current smoking & $46(30)$ & $416(34)$ & 0.35 \\
\hline Diabetes mellitus & $58(38)$ & $361(29)$ & 0.03 \\
\hline \multicolumn{4}{|l|}{ Medical history } \\
\hline Previous stroke or TIA & $8(5)$ & $58(5)$ & 0.78 \\
\hline Previous CABG & $8(5)$ & $46(4)$ & 0.37 \\
\hline Previous PCl & $17(11)$ & $147(12)$ & 0.76 \\
\hline Previous MI & $15(10)$ & $133(11)$ & 0.70 \\
\hline Peripheral artery disease & $13(9)$ & $61(5)$ & 0.06 \\
\hline Chronic kidney disease & $4(3)$ & $25(2)$ & 0.64 \\
\hline Chronic obstructive lung disease & $3(2)$ & $14(1)$ & 0.38 \\
\hline History of cancer & $5(3)$ & $60(5)$ & 0.37 \\
\hline \multicolumn{4}{|l|}{ Drugs before index acute $\mathrm{MI}$} \\
\hline Antiplatelet agent & $32(21)$ & $300(24)$ & 0.34 \\
\hline Statin & $38(25)$ & $330(27)$ & 0.60 \\
\hline$\beta$ blocker & $33(22)$ & $310(25)$ & 0.33 \\
\hline ACE inhibitor & $24(16)$ & $173(14)$ & 0.59 \\
\hline Angiotensin receptor blocker & $27(18)$ & $197(16)$ & 0.61 \\
\hline \multicolumn{4}{|l|}{ Index acute $\mathrm{MI}$} \\
\hline STEMI & $80(52)$ & $700(57)$ & 0.28 \\
\hline Atrial fibrillation on first electrocardiogram & $5(3)$ & $40(3)$ & 0.99 \\
\hline Mean (SD) GRACE score, 6 months & $106(29)$ & $101(26)$ & 0.07 \\
\hline Mean (SD) GRACE score 2.0, simplified 3 years & $0.86(0.15)$ & $0.88(0.12)$ & 0.008 \\
\hline Median (IQR) maximal CK, IU/L & $428(190-1078) ;(n=129)$ & 520 (203 to 1340); $(n=1089)$ & 0.108 \\
\hline Median (IQR) LVEF, \% & $60(50-65) ;(n=112)$ & $57(50-64) ;(n=949)$ & 0.238 \\
\hline Coronary angiography & $143(93)$ & $1194(97)$ & 0.02 \\
\hline \multicolumn{4}{|l|}{ Reperfusion therapy in STEMI: } \\
\hline Fibrinolysis & $28(35)$ & $222(32)$ & 0.793 \\
\hline Primary $\mathrm{PCl}$ & $29(36)$ & $278(40)$ & \\
\hline $\mathrm{PCl}$ & $114(75)$ & $960(78)$ & 0.32 \\
\hline $\mathrm{PCl}$ in first 48 hours & $75(49)$ & $659(54)$ & 0.29 \\
\hline Multivessel CAD & $54(35)$ & $520(42)$ & 0.19 \\
\hline LMWH in first 48 hours & $116(76)$ & $872(71)$ & 0.20 \\
\hline Clopidogrel in first 48 hours & $142(93)$ & $1158(94)$ & 0.51 \\
\hline$\beta$ blocker in first 48 hours & $131(86)$ & $1091(89)$ & 0.26 \\
\hline LVEF $>50 \%$ & $81 / 112(72)$ & $662 / 950(70)$ & 0.56 \\
\hline Recurrent MI & $1(1)$ & $16(1)$ & 0.49 \\
\hline Stroke & $1(1)$ & $3(0.2)$ & 0.37 \\
\hline Major bleeding & $4(3)$ & $12(1)$ & 0.07 \\
\hline Ventricular fibrillation & $0(0)$ & $14(1)$ & 0.18 \\
\hline \multicolumn{4}{|l|}{ Recurrent acute MI or stroke } \\
\hline During first year & $6(4)$ & $41(3)$ & 0.70 \\
\hline \multicolumn{4}{|l|}{ Drugs at 1 year } \\
\hline Statin & $99(65)$ & $1094(89)$ & $<0.001$ \\
\hline Aspirin & $107(70)$ & $1094(89)$ & $<0.001$ \\
\hline Clopidogrel & $90(59)$ & $964(78)$ & $<0.001$ \\
\hline ACE inhibitor & $74(48)$ & $747(61)$ & 0.003 \\
\hline Angiotensin receptor blocker & $18(12)$ & $180(15)$ & 0.34 \\
\hline \multicolumn{4}{|l|}{ Type of $\beta$ blocker at 1 year } \\
\hline Acebutolol & - & $270(22)$ & - \\
\hline Atenolol & - & $401(33)$ & - \\
\hline Bisoprolol & - & $361(29)$ & - \\
\hline Metoprolol & - & $91(7)$ & - \\
\hline Other/unknown & - & $107(9)$ & - \\
\hline
\end{tabular}


compared with $36 \%$ of those taking statins at one year. Propensity score matched cohorts showed consistent results (supplementary fig F). Five year risk of death, recurrent myocardial infarction, or stroke was $21.3 \%$ in those who had stopped statins at one year versus $10.4 \%$ in those with continued statin treatment: crude hazard ratio 0.46 ( 0.31 to $0.68 ; \mathrm{P}<0.001)$; adjusted hazard ratio 0.57 (0.37 to $0.88 ; \mathrm{P}=0.01)$.

\section{Discussion}

The main findings of our study are that early use of $\beta$ blocker treatment is related to a substantial reduction in risk of 30 day mortality in patients with acute myocardial infarction without heart failure, whereas its use at discharge is associated with a non-significant reduction in one year mortality. Stopping $\beta$ blocker treatment in the year after the acute myocardial infarction was not related to a higher risk of mortality up to five years, in contrast with the increased five year mortality observed in those patients who stopped statin treatment. No heterogeneity existed across subgroups, and the data were consistent whatever the type and dose of $\beta$ blocker used. These observations suggest a progressively decreasing benefit of $\beta$ blocker treatment over time.

\section{Initial randomised trials and their effect on guidelines}

Most of the evidence on $\beta$ blockers in patients with acute myocardial infarction dates back to the pre-reperfusion era; $\beta$ blockers reduced mortality both acutely and in the long term. ${ }^{3}$ This has been the basis for a high level of recommendations in both European and American guidelines. ${ }^{1213}$ Recently, however, European guidelines, taking into account the fact that evidence on the usefulness of $\beta$ blockers in the contemporary era was lacking, have downgraded the level of recommendation from class I to IIa, ${ }^{8}$ whereas the American guidelines still give the highest level of recommendation for $\beta$ blockers, both in ST elevation myocardial infarction and non-ST elevation acute coronary syndromes. ${ }^{67}$

The most recent meta-analysis of $\beta$ blockers in acute myocardial infarction found that these agents reduced mortality before the reperfusion era, whereas this was no longer the case in the reperfusion era. ${ }^{9}$ Data in the reperfusion era, however, mostly rely on the results of the large COMMIT trial, ${ }^{4}$ in which metoprolol (intravenous followed by oral administration) had no effect on mortality but reduced the risk of recurrent myocardial infarction at 28 days, in a population in whom primary percutaneous coronary intervention was not used and fibrinolysis was administered in only $55 \%$; of note, and in keeping with our results, early $\beta$ blocker treatment was associated with numerically lower 28 day mortality in patients who were Killip class I at entry. Overall, however, very little information on the effects of $\beta$ blockers beyond the first month in the reperfusion era is available from randomised trials.

\section{Comparison with other observational studies}

Most recent information comes from observational cohorts. Twenty years ago, the Cooperative Cardiovascular project found that one third of more than 200000
Medicare patients with acute myocardial infarction, of whom only a minority had reperfusion therapy, were discharged taking $\beta$ blockers; prescription of $\beta$ blockers at discharge was associated with improved survival at 24 months, particularly in high risk groups, and to a greater extent in the case of non-transmural infarction. ${ }^{14}$ Other registries, such as GRACE in non-ST elevation myocardial infarction patients or the Korean registry in patients with primary percutaneous coronary intervention, showed that $\beta$ blocker prescription at discharge was associated with lower mortality at six months (GRACE) and up to three years (Korean registry). ${ }^{1516}$ In the Prospective Registry Evaluating Myocardial Infarction: Event and Recovery (PREMIER) registry, ${ }^{17}$ early discontinuation of $\beta$ blockers (one month after acute myocardial infarction) was associated with a twofold increase in mortality at one year. In the Ontario reimbursement database, ${ }^{18}$ poor adherence to $\beta$ blockers ( $<40 \%$ of days covered) in the year after acute myocardial infarction in older patients was associated with increased mortality (hazard ratio 1.13, 95\% confidence interval 1.03 to 1.25). A similar trend was observed in the Reduction of Atherothrombosis for Continued Health (REACH) registry, ${ }^{19}$ for patients with a myocardial infarction within one year of inclusion (hazard ratio for cardiovascular death, myocardial infarction, or stroke 0.79 ( 0.60 to 1.04 ) in patients receiving $\beta$ blockers). Thus, the data from our study on one year mortality according to prescription of $\beta$ blockers at discharge seem to be consistent with previous findings suggesting the beneficial effect of early $\beta$ blocker treatment on survival in the first months after the acute episode, even in contemporary populations with high rates of primary percutaneous coronary intervention. Recently, the Outcomes of $\beta$-blocker Therapy After Myocardial Infarction (OBTAIN) registry studied the association between dose of $\beta$ blocker and two year survival in 6682 patients discharged after an ST elevation or non-ST elevation myocardial infarction. ${ }^{20}$ Mortality was lower in patients discharged taking $\beta$ blockers but was not significantly related to $\beta$ blocker dose.

Data on the role of $\beta$ blocker treatment after the first months following acute myocardial infarction are even more limited and suggest that it has less (if any) effect on major cardiovascular outcomes. In the REACH registry, ${ }^{19}$ the risk of cardiovascular death, myocardial infarction, or stroke at 44 months associated with $\beta$ blocker use did not differ either in the whole cohort of patients with previous myocardial infarction (hazard ratio $0.90,0.79$ to 1.03 ) or among those with coronary artery disease and no history of myocardial infarction (0.92, 0.79 to 1.08). In both groups, the risk of death was slightly, and not significantly, reduced in patients treated with $\beta$ blockers, whereas the risk of myocardial infarction was slightly increased. Specific results in patients with a history of acute myocardial infarction more than one year before inclusion were not reported. Likewise, in the Kaiser Permanente database analysis of patients with newly diagnosed coronary artery disease (acute coronary syndrome or myocardial revascularisation), ${ }^{21}$ mortality was significantly higher when the patients were not taking $\beta$ blockers, compared with taking $\beta$ blockers, but with a strong interaction with the 
presence of recent myocardial infarction. $\beta$ blockers were significantly associated with decreased mortality in patients with a recent myocardial infarction (hazard ratio $0.85,0.79$ to 0.92 ), but no increase in mortality was seen in patients with either an older history of myocardial infarction or no myocardial infarction (hazard ratio 1.02, 0.91 to 1.15). Again, specific results in patients with an acute myocardial infarction more than one year previously were not reported.

Finally, when we analysed the outcomes of patients with a history of heart failure or low ejection fraction (that is, those not included in the main analysis) who had stopped $\beta$ blockers during the first year, we found results concordant with what would be expected from the results of randomised trials in patients with heart failure/low ejection fraction, with a strong association with a higher five year mortality (adjusted hazard ratio 2.11, 1.16 to 3.83; $\mathrm{P}=0.014)$.

\section{Limitations of study}

As in all observational studies, this analysis has limitations. At the acute stage, the most severely ill patients less often receive $\beta$ blockers, and statistical techniques may not be sufficient to adjust completely for these confounders, thereby increasing the measured favourable association between early $\beta$ blocker treatment and mortality. Conversely, because only a minority of patients did not receive $\beta$ blockers at discharge and a smaller minority still discontinued $\beta$ blockers during the first year, we cannot exclude the possibility that unusual, and therefore unmeasured, confounders explaining the absence of prescription or discontinuation of treatment existed. However, FAST-MI provided very detailed characterisation of the patients, making it unlikely that major confounders were not recorded. In addition, unrecorded confounders would probably have been similar for statins and $\beta$ blockers.

Also, we did not do a formal sample size calculation for our analysis, and the limited size of our population increases the risk of a type B error and of an underestimation of the potential benefit of $\beta$ blockers, especially during the first year. Therefore, the lack of statistical significance for $\beta$ blocker prescription at discharge cannot be considered proof of its lack of effect. Likewise, subgroup analyses or analyses according to type or dose of $\beta$ blockers should be interpreted with caution.

More importantly, most observational data have shown that patients who adhere to preventive drugs are more "health conscious" than those who do not adhere, ${ }^{22-24}$ with a less severe profile, including their socioeconomic status, and an overall better prognosis, thus leading to a "healthy user" bias (in other words, adherence to any drug in itself is associated with higher survival). In this regard, the striking difference between mortality in patients who stopped $\beta$ blockers and those who stopped statins (granting that patients stopping $\beta$ blockers were also more likely to stop other recommended drugs such as statins) suggests that the lack of prognostic significance of $\beta$ blocker discontinuation at one year is unlikely to have been affected by such a bias.

\section{Conclusions}

The results presented suggest a decrease over time in the effect of $\beta$ blocker treatment on survival in patients with acute myocardial infarction without heart failure or left ventricular dysfunction. Early use of $\beta$ blockers at the acute stage of myocardial infarction was associated with a substantial decrease in 30 day mortality, whereas prolonged $\beta$ blocker treatment beyond one year is unlikely to improve survival.

\section{AUTHOR AFFILIATIONS}

'Department of Cardiology, Hôpital Européen Georges Pompidou, 75015 Paris, France

${ }^{2}$ Assistance Publique-Hôpitaux de Paris, Paris, France

3Université Paris-Descartes, Paris, France

${ }^{4}$ Department of Critical Care, Hôpital Européen Georges Pompidou, Paris, France

5Department of Dermatology and Allergology, Tenon Hospital, Paris, France

6Sorbonne University, Université Pierre et Marie Curie (UPMC-Paris 06), Paris, France

7INSERM U1135-CIMI, Paris, France

${ }^{8}$ Hôpital Bichat, Paris, France

?Université Paris Diderot, Paris, France

${ }^{10}$ INSERM U 698, Paris, France

${ }^{11}$ Hôpital cardiologique du Haut Levêque, Pessac, France

${ }^{12}$ Université Bordeaux Segalen, Bordeaux, France

${ }^{13}$ Hôpital du Bocage, Dijon, France

${ }^{14}$ Université de Bourgogne, Dijon, France

${ }^{15}$ Hôpital St Joseph et St Luc, Lyon, France

${ }^{16}$ Hôpital cardiologique Louis Pradel, Lyon, France

${ }^{17}$ Université Lyon 1, Lyon, France

${ }^{18} \mathrm{Clinique}$ St Gatien, Tours, France

${ }^{19}$ Groupe Hospitalier Intercommunal Le Raincy-Montfermeil, Montfermeil, France

${ }^{20}$ Hôpital Jean Minjoz, Besançon, France

${ }^{21}$ Université de Franche Comté, Besançon, France

${ }^{22}$ Department of Cardiology B and Epidemiology, Toulouse

University Hospital, Toulouse, France

${ }^{23}$ UMR INSERM 1027, Toulouse, France

${ }^{24}$ Institut Lorrain du Cœur et des Vaisseaux

${ }^{25}$ Université de Lorraine, Nancy, France

${ }^{26}$ Hôpital Saint Antoine, Department of Clinical Pharmacology and Unité de Recherche Clinique (URCEST), Paris, France

${ }^{27}$ Université Pierre et Marie Curie (UPMC-Paris 06), Paris, France ${ }^{28}$ INSERM U-698, Paris, France

Contributors: ND and TS planned and designed the study; they contributed equally to the work. EP, ND, and TS were responsible for data management and analysis. EP, ER, ND, and TS drafted the manuscript. All authors revised the paper critically for important intellectual content and approved the final version of the manuscript. ND supervised the study and is the guarantor.

We thank the patients who agreed to participate in the survey, all the physicians who took care of the patients at the participating hospitals, and all personnel involved in the registry organisation. Special thanks go to Vincent Bataille for his careful data management, to Benoît Pace (Société Française de Cardiologie) for his invaluable assistance in designing the electronic case report form, and to Geneviève Mulak (Société Française de Cardiologie) who, with the help of Elodie Drouet, supervised the patients' follow-up. We thank Pascal Guéret for his assistance in classifying the follow-up events. We also acknowledge the work of the ICTA contract research organisation (Fontaine-lèsDijon, France). A complete list of participating centres and investigators can be found in reference 10 .

Funding: FAST-MI is a registry of the French Society of Cardiology, supported by unrestricted grants from Pfizer and Servier. Additional support was obtained from a research grant from the French Caisse Nationale d'Assurance Maladie. 
Competing interests: All authors have completed the ICMJE uniform disclosure form at www.icmje.org/coi_disclosure.pdf (available on request from the corresponding author) and declare: EP has received speaker, board membership, and consulting fees from Amgen, AstraZeneca, Bayer, Daiichi Sankyo, Lilly, MSD, and Sanofi-Aventis; SC has received grants from AstraZeneca, Boehringer Ingelheim, Boston Scientific, Medtronic, and Servier; GS has received institutional research grant support from NYU School of Medicine, Sanofi-Aventis, and Servier and consulting/advisory board fees from Ablynx, Amarin, Astellas, AstraZeneca, Bayer, Boehringer Ingelheim, BMS, Daiichi-Sankyo-Lilly, GSK, Medtronic, MSD, Novartis, Otsuka, Pfizer, Roche, Sanofi-Aventis, Servier, and The Medicines Company and is a stockholder and co-founder of Aterovax; FS has received grant support to his institution and travel support for scientific meetings from AstraZeneca, Boehringer-Ingelheim, Daiichi-Sankyo, Lilly, Medtronic, Pfizer; Sanofi-Aventis, Servier, and Takeda; JF has received grants and speaker fees from AstraZeneca, Genzyme, Merck, Novartis, and Servier. TS has received research grants from Astra-Zeneca, DaiichiSankyo, Eli-Lilly, Glaxo-Smith-Kline, MSD, Novartis, Pfizer, Sanofi-Aventis, and Servier and speaker and consulting fees from AstraZeneca, Bayer-Schering, Eli-Lilly, and Sanofi-Aventis; ND has received research grants from AstraZeneca, Daiichi-Sankyo, Eli-Lilly, Glaxo-Smith-Kline, MSD, Novartis, Pfizer, Sanofi-Aventis, Servier, and The Medicines Company and advisory panel or lecture fees from AstraZeneca, Boehringer-Ingelheim, Bristol-Myers Squibb, Eli-Lilly, Menarini, Merck-Serono, Novo-Nordisk, Servier, and Sanofi-Aventis; no other relationships or activities that could appear to have influenced the submitted work.

Ethical approval: The study protocol and consent documents were approved by an independent ethics committee (Committee for the Protection of Human Subjects in Biomedical Research of Saint Antoine University Hospital; NCT 00673036). All patients gave informed consent.

Data sharing: The authors commit to making the relevant anonymised patient level data available on reasonable request.

Transparency: The lead author affirms that this manuscript is an honest, accurate, and transparent account of the study being reported; that no important aspects of the study have been omitted; and that any discrepancies from the study as planned (and, if relevant, registered) have been explained.

This is an Open Access article distributed in accordance with the Creative Commons Attribution Non Commercial (CC BY-NC 3.0) license, which permits others to distribute, remix, adapt, build upon this work non-commercially, and license their derivative works on different terms, provided the original work is properly cited and the use is noncommercial. See: http://creativecommons.org/licenses/by-nc/3.0/.

1 Brophy JM, Joseph L, Rouleau JL. Beta-blockers in congestive heart failure. A Bayesian meta-analysis. Ann Intern Med 2001;134:55060. doi:10.7326/0003-4819-134-7-200104030-00008.

2 Fauchier L, Pierre B, de Labriolle A, Babuty D. Comparison of the beneficial effect of beta-blockers on mortality in patients with ischaemic or non-ischaemic systolic heart failure: a meta-analysis of randomised controlled trials. Eur J Heart Fail 2007:9:1136-9. doi:10.1016/j.ejheart.2007.09.003.

3 Freemantle N, Cleland J, Young P, Mason J, Harrison J. beta Blockade after myocardial infarction: systematic review and meta regression analysis. BM/1999:318:1730-7. doi:10.1136/bmj.318.7200.1730.

4 Chen ZM, Pan HC, Chen YP, et al. COMMIT (ClOpidogrel and Metoprolol in Myocardial Infarction Trial) collaborative group. Early intravenous then oral metoprolol in 45,852 patients with acute myocardial infarction: randomised placebo-controlled trial. Lancet 2005;366:1622-32. doi:10.1016/S0140-6736(05)67661-1.

5 Hamm CW, Bassand J-P. Agewall S, et al. European Society of Cardiology. [ESC guidelines for the management of acute coronary syndromes in patients presenting without persistent ST-segment elevation. The Task Force for the management of acute coronary syndromes (ACS) in patients presenting without persistent ST-segment elevation of the European Society of Cardiology (ESC)].G Ital Cardiol (Rome) 2006;2012:171-228

6 Anderson JL, Adams CD, Antman EM, et al. 2012 ACCF/AHA focused update incorporated into the ACCF/AHA 2007 guidelines for the management of patients with unstable angina/non-ST-elevation myocardial infarction: a report of the American College of Cardiology Foundation/American Heart Association Task Force on Practice Guidelines. J Am Coll Cardiol 2013;61:e179-347. doi:10.1016/j.jacc.2013.01.014

7 O'Gara PT, Kushner FG, Ascheim DD, et al. American College of Emergency Physicians Society for Cardiovascular Angiography and Interventions. 2013 ACCF/AHA guideline for the management of ST-elevation myocardial infarction: a report of the American College of Cardiology Foundation/ American Heart Association Task Force on Practice Guidelines. J Am Coll Cardiol 2013;61:e78-140. doi:10.1016/j.jacc.2012.11.019.
8 Steg PG, James SK, Atar D, et al. Task Force on the management of ST-segment elevation acute myocardial infarction of the European Society of Cardiology (ESC). ESC Guidelines for the management of acute myocardial infarction in patients presenting with ST-segment elevation. Eur Heart J 2012;33:2569-619. doi:10.1093/eurheartj/ ehs215.

9 Bangalore S, Makani H, Radford M, et al. Clinical outcomes with $\beta$-blockers for myocardial infarction: a meta-analysis of randomized trials. Am J Med 2014;127:939-53. doi:10.1016/j.amjmed.2014.05.032.

10 Cambou J-P, Simon T, Mulak G, Bataille V, Danchin N. The French registry of Acute ST elevation or non-ST-elevation Myocardial Infarction (FAST-MI): study design and baseline characteristics. Arch Mal Coeur Vaiss 2007;100:524-34.

11 Danchin N, Puymirat E, Steg PG, et al. FAST-MI 2005 Investigators. Five-year survival in patients with ST-segment-elevation myocardial infarction according to modalities of reperfusion therapy: the French Registry on Acute ST-Elevation and Non-ST-Elevation Myocardial Infarction (FAST-MI) 2005 Cohort. Circulation 2014;129:1629-36 doi:10.1161/CIRCULATIONAHA.113.005874.

12 Van de Werf F, Bax J, Betriu A, et al. ESC Committee for Practice Guidelines (CPG). Management of acute myocardial infarction in patients presenting with persistent ST-segment elevation: the Task Force on the Management of ST-Segment Elevation Acute Myocardial Infarction of the European Society of Cardiology. Eur Heart 2008;29:2909-45. doi:10.1093/eurheartj/ehn416.

13 Antman EM, Anbe DT, Armstrong PW, et al. American College of Cardiology American Heart Association Canadian Cardiovascular Society. ACC/AHA guidelines for the management of patients with ST-elevation myocardial infarction--executive summary. A report of the American College of Cardiology/American Heart Association Task Force on Practice Guidelines (Writing Committee to revise the 1999 guidelines for the management of patients with acute myocardial infarction). J Am Coll Cardiol 2004;44:671-719. doi:10.1016/j. jacc.2004.07.002.

14 Gottlieb SS, McCarter RJ, Vogel RA. Effect of beta-blockade on mortality among high-risk and low-risk patients after myocardial infarction. N Engl/ Med 1998;339:489-97. doi:10.1056/ NEJM199808203390801.

15 Emery M, López-Sendón J, Steg PG, et al. GRACE Investigators. Patterns of use and potential impact of early beta-blocker therapy in non-ST-elevation myocardial infarction with and without heart failure: the Global Registry of Acute Coronary Events. Am Heart) 2006;152:1015-21. doi:10.1016/j.ahj.2006.08.024.

16 Choo EH, Chang K, Ahn Y, et al. Benefit of $\beta$-blocker treatment for patients with acute myocardial infarction and preserved systolic function after percutaneous coronary intervention. Heart 2014;100:492-9. doi:10.1136/heartjnl-2013-305137.

17 Ho PM, Spertus JA, Masoudi FA, et al. Impact of medication therapy discontinuation on mortality after myocardial infarction. Arch Intern Med 2006;166:1842-7. doi:10.1001/archinte.166.17.1842.

18 Rasmussen JN, Chong A, Alter DA. Relationship between adherence to evidence-based pharmacotherapy and long-term mortality after acute myocardial infarction. JAMA 2007;297:177-86. doi:10.1001/ jama.297.2.177.

19 Bangalore S, Steg G, Deedwania P, et al. REACH Registry Investigators. $\beta$-Blocker use and clinical outcomes in stable outpatients with and without coronary artery disease. JAMA 2012;308:1340-9. doi:10.1001/jama.2012.12559.

20 Goldberger JJ, Bonow RO, Cuffe M, et al. OBTAIN Investigators. Effect of Beta-Blocker Dose on Survival After Acute Myocardial Infarction. J Am Coll Cardiol 2015;66:1431-41. doi:10.1016/j.jacc.2015.07.047.

21 Andersson C, Shilane D, Go AS, et al. $\beta$-blocker therapy and cardiac events among patients with newly diagnosed coronary heart disease. J Am Coll Cardiol 2014:64:247-52. doi:10.1016/i.jacc.2014.04.042.

22 Fonarow GC, French W], Parsons LS, Sun H, Malmgren JA. Use of lipid-lowering medications at discharge in patients with acute myocardial infarction: data from the National Registry of Myocardial Infarction 3. Circulation 2001;103:38-44. doi:10.1161/01. CIR.103.1.38.

23 Dormuth CR, Patrick AR, Shrank WH, et al. Statin adherence and risk of accidents: a cautionary tale. Circulation 2009;119:2051-7. doi:10.1161/CIRCULATIONAHA.108.824151.

24 Danchin N, Neumann A, Tuppin P, et al. Impact of free universal medical coverage on medical care and outcomes in low-income patients hospitalized for acute myocardial infarction: an analysis from the FrenchNational Health Insurance system. Circ Cardiovasc Qual Outcomes 2011;4:619-25. doi:10.1161/ CIRCOUTCOMES.111.961193.

(C) BMJ Publishing Group Ltd 2016

Appendix and supplementary tables/figures 